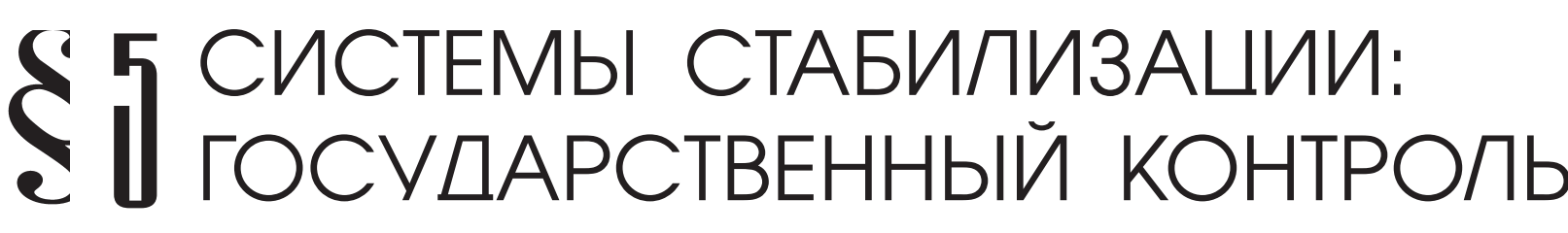

Абатуров А.И

\section{НОРМАТИВНАЯ РЕГЛАМЕНТАЦИЯ ПОСТПЕНИТЕНЦИАРНОГО СОПРОВОЖДЕНИЯ В СОВРЕМЕННОЙ РОССИИ}

\begin{abstract}
Аннотация: Предметом исследования являются общественные отношения возникающие в процессе оказания помощи лицам, освобожденным из мест лишения свободы уголовно-исполнительной системы России. Автор подробно рассматривает актуальные проблемы возникающие при оказании социальной помощи и поддержки гражданам, освобождающимся из мест лишения свободы. Особое внимание уделяется вопросам современной законодательной регламентации постпенитенциарного сопровождения, анализируются основные причины недостатков и упущений в этой области, так как среди причин, способствующих росту рецидивной преступности, одно из основных мест занимает отсутствие государственно-правового механизма поддержки лии, отбывших уголовное наказание в виде лишения свободы. Методологическую основу статьи составил диалектический метод познания действительности. В проиессе работы также использовались общенаучные и спечиальные методы познания: сравнительно-правовой при анализе новых и ранее действовавших уголовно-правовых норм, а также уголовно-исполнительного законодательства. Научная новизна исследовании обусловлена тем, что оно представляет собой работу, имеющую теоретическое и прикладное значение в сфере создания стройной, работоспособной и эффективной системы государственной поддержки лии, отбывших уголовное наказание в виде лишения свободы, создание которой позволит наиболее эффективно как с экономической, так и социальной точек зрения целенаправленно укрепить стабильность в обществе, обеспечить его защищенность от внутренней угрозы, создать условия жизни этих лии в социуме, предупредить совершение ими новых преступлений.
\end{abstract}

Ключевые слова: Рецидив, социальная реабилитация, субъекты Российской Федерации, региональные программы, постпенитенциарное сопровождение, исправительные учреждения, осужденые, пробаиия, лишение свободы, правоохранительные органы.

Abstract: The subject of this research is the public relations arising in the process of assisting persons released from prison of the Russia penal system. The author carefully examines the actual problems arising in the provision of social assistance and support to citizens released from prison. The author gives special attention to the current legislative regulation of the post-penitentiary support, analyzes the main reasons for the shortcomings and deficiencies in this area. Among the main factors contributing to the growth in recidivism is the absence of state legal mechanism for providing support to citizens released from prison. The methodological basis of this work consisted of the dialectical method of cognition of reality, as well as general scientific and special methods of cognition: a comparative legal analysis in the new and previously existing criminal law and penal legislation. The scientific novelty of this work consists in the fact that it carries the theoretical and practical importance in creating a coherent, workable and effective system of state support for persons who have served a criminal sentence of imprisonment, the creation of which will improve both economic, and social perspectives, strengthen the stability in the society, ensure its protection against internal threats, create living conditions for these individuals in the society, and prevent the commission of new crimes.

Keywords: Law enforcement, Incarceration, Probation, Relapse, Social rehabilitation, Subjects of the Russian Federation, Regional programs, Post-penitentiary support, Correctional facilities, Convicts.

ктуальность проблемы постпенитенциарной адаптации в современных условиях развития российского правового государства приобретает особое значение.
Гарантированная социальная защита и создание равных возможностей для реализации интеллектуального потенциала каждым гражданином являются основополагающими конституционными принципами 


\section{Системы стабилизации: государственный контроль}

в России. Особое внимание следует уделять лицам, оказавшимся в трудной жизненной ситуации. К ним, безусловно, относятся лица, освобожденные из мест лишения свободы и утратившие навыки полноценного социального общения.

В этих условиях все более злободневной становится необходимость создания гармоничной, работоспособной и результативной системы постпенитенциарной поддержки со стороны государства граждан, освобожденных из мест лишения свободы.

В определенной мере решению проблемы в общероссийском масштабе может способствовать создание соответствующего общественно-государственного механизма оказания помощи лицам, освобожденным из мест лишения свободы, с участием субъектов государственной власти и негосударственных общественных объединений Российской Федерации.

Чтобы определить основные тенденции развития института поспенитенциарного сопровождения на уровне субъектов Российской Федерации, мы проанализировали региональные программы социальной реабилитации лиц, освободившихся из мест лишения свободы. С этой целью мы исследовали действующие программы субъектов Российской Федерации: Республики Адыгеи [1], Алтай [2], Бурятии[3], Ингушетии [4], Алтайского [5], Забайкальского [6], Камчатского [7] и Ставропольского края [8], Белгородской [9], Воронежской [10], Кировской [11], Московской, Оренбургской [12], Омской [13], Самарской [14] и Сахалинской областей [15].

Срок действия программ ранжируется от 3 лет (Республики Адыгея и Ингушетия, Самарская области), 4 лет (Алтайский и Забайкальский края, Сахалинская область), 5 лет (Республики Алтай, Камчатский край, Воронежская область), 8 лет (Белгородская). Различный срок действия программ перечисленных субъектов Российской Федерации свидетельствует о различных подходах, способах и путях решения вопросов, связанных с долгосрочным планированием региональными органами исполнительной власти в области оказания постпенитенциарной помощи лицам, освобожденным из мест лишения свободы.

Каждая региональная программа имеет конкретные цели реализации поспенитенциарного сопровождения лиц, освобожденных из мест лишения свободы, с учетом региональных особенностей. Так, Республики Адыгея и Алтай поставили перед собой цель сформировать условия для социальной реабилитации и адаптации граждан, отбывших наказание в виде лишения свободы. В Ингушетии, Камчатском крае, Курской, Московской и Самарской областях - сформировать условия для социальной реабилитации и адаптации граждан, отбывших наказание в виде лишения свободы, и сокращение факторов, способствующих росту рецидивной преступности.

В Ставорапольском крае целью закона является ориентация лиц, освобожденных из учреждений уголовно-исполнительной системы, на соблюдение принятых в обществе правил и норм поведения, а также преодоление ими негативных последствий лишения свободы в учреждениях уголовно-исполнительной системы.

Представляет интерес цель сформулированная в программе Правительства Сахалинской области «О содействии социальной реабилитации лицам, отбывшим наказание в виде лишения свободы, и развитию уголовно-исполнительной системы Сахалинской области на 2013 - 2016 годы», которой является создание условий для безопасной жизнедеятельности населения Сахалинской области, обеспечение надежной защиты личности, общества и государства от преступных посягательств.

Иная цель обозначена в Сахалинской восьмилетней подпрограмме «Обеспечение общественного порядка, противодействие преступности и незаконному обороту наркотиков в Сахалинской области на 2013 - 2020 годы» в которой сформулированно сокращение рецидива преступлений, совершенных лицами, отбывшими наказание в виде лишения свободы, за счет повышения эффективности социальной и психологической работы в местах лишения свободы и развития системы постпенитенциарной помощи таким лицам [16].

И для реализации этих целей планируется выделить из областного бюджета 577 тыс 063 рубля.

Наиболее значимые мероприятия в анализируемых программах.

- предоставление учреждениями социальной защиты населения надомных социальных услуг одиноким нетрудоспособным гражданам, отбывшим наказание в виде лишения свободы (Республика Адыгея);

- обеспечение гласности в деятельности уголовно-исполнительной системы, ее подконтрольности институтам гражданского общества, создание условий для участия общественности в решении стоящих перед уголовно-исполнительной системой задач (Сахалин);

- информирование лиц, освобожденных из учреждений уголовно-исполнительной системы, о положении на рынке труда, видах и порядке предоставления государственных услуг в сфере занятости населения и едицинское обследование лиц, освобожденных из учреждений уголовно-исполнительной систе- 


\section{Право и политика $11(203) \cdot 2016$}

мы, в медицинских организациях государственной системы здравоохранения Ставропольского края (Ставропольский край).

В Красноярске с января 2013 года по инициативе ГУФСИН начала работу служба социального сопровождения лиц, освобожденных из мест лишения свободы. По своей сути такая служба является аналогом зарубежной службы пробации и решает определенные задачи, такие как оказание содействия лицам, освободившимся из мест лишения свободы, в решении вопросов трудового и бытового устройства, восстановление социально-полезных связей и оказание им бесплатной юридической помощи.

14 - 15 мая 2015 г. в Воронеже на межрегиональной конференции с представителями органов исполнительной власти, членами общественных наблюдательных комиссий и руководителями общественных объединений были обсуждены механизмы адаптации и ресоциализации лиц, освободившихся из мест лишения свободы. В ходе конференции докладчики неоднократно указывали на отсутствие единого документа федерального уровня в котором был бы сформулирован единый подход к постпенитенциарному сопровождению. Предполагалось, что в развитие этого положения будет принят Федеральный закон «О социальной помощи лицам, освобождённым от наказания, и контроле за их поведением», проект которого был подготовлен и внесён в Государственную Думу Российской Федерации в 1997 г. Законопроектом определялись: порядок оказания помощи в трудовом и бытовом устройстве лицам, отбывшим наказание; компетенция и направления деятельности органов местного самоуправления по оказанию такой помощи; квота рабочих мест на предприятиях для освобождённых граждан, нуждающихся в трудоустройстве, и экономические стимулы для таких предприятий; создание органами местного самоуправления центров социальной адаптации, ночлежных домов, а также специальных фондов материальной помощи освобождённым. Однако данный законопроект был снят с рассмотрения Государственной Думы из-за отсутствия финансовых средств на его реализацию.

В настоящее время, при отсутствии такого Федерального закона, а также единой нормативной правовой базы оказания помощи в социальной адаптации лицам, освобождённым от наказания, основная нагрузка в ее осуществлении легла на органы власти субъектов Российской Федерации и органы местного самоуправления (вышестоящий анализ документов тому подтверждение).
Несмотря на отсутствие закона об оказании постпенитенциарной помощи, действующее российское законодательство достаточно подробно регулирует отдельные вопросы, связанные с ее осуществлением.

Важное значение для регулирования рассматриваемых отношений имеют такие концептуальные документы, как Стратегия национальной безопасности Российской Федерации до 2020 года [17], Концепция долгосрочного социально-экономического развития Российской Федерации на период до 2020 года [18], Федеральная целевая программа «Развитие уголовно-исполнительной системы (2007 - 2016 годы)» [19], Государственная программа Российской Федерации «Юстиция» [20], «Концепция развития уголовно-исполнительной системы Российской Федерации до 2020 года» [21].

В названных документах содержатся общие положения, касающиеся государственной поддержки лиц, отбывших уголовное наказание в виде лишения свободы. Так, в перечне основных мероприятий Государственной программы Российской Федерации «Юстиция» сформулировано, что до 2020 года государственные органы должны оказать лицам, освободившимся из мест лишения свободы, содействие в решении проблем трудового и бытового устройства; расширить сеть центров социальной реабилитации для лиц, освобождающихся из мест лишения свободы; предоставить для лиц, заканчивающих отбывание длительных сроков лишения свободы, возможность прохождения специального тренинга, включающего информацию об изменениях в обществе, новых формах социальной жизни, а для некоторых категорий осужденных - предоставить возможность перевода в колонию-поселение с разрешением кратковременных выездов к месту предполагаемого жительства. С этой целью планируется в период с 2013 по 2020 гг. освоить денежные средства в сумме 360475 237,8 рублей [22].

Анализ «Концепциии развития уголовно-исполнительной системы Российской Федерации до 2020 года» показал, что законодатель одной из целью реформирования УИС ставит проведение в местах лишения свободы мероприятий в цуелях адаптации в обществе освободившихся осужденных, в том числе с участием гражданского общества.

Так, в рамках совершенствования отдельных направлений деятельности уголовно-исполнительной системы планируется:

- обучение осужденных профессиям в рамках реализации основных профессиональных образовательных программ и основных программ профессионального обучения, востребованным на рынке труда, совершенствование профессио- 


\section{Системы стабилизации: государственный контроль}

нальных навыков, позволяющих трудоустроиться после освобождения;

- определение прогнозных потребностей в работах и профессиях рабочих, востребованных на рынке труда;

- осуществление профессионального обучения осужденных и обеспечение получения ими среднего профессионального образования по программам подготовки квалифицированных рабочих, служащих с учетом результатов мониторинга прогнозных потребностей в работах и профессиях рабочих в учреждениях уголовно-исполнительной системы и региональных рынков труда в целях обеспечения гарантий трудоустройства и возвращения в общество законопослушных граждан

Сотрудники уголовно-исполнительных инспекций, исполняющие наказание без изоляции осужденных от общества должны проводить мероприятия в целях адаптации освободившихся осужденных в обществе. Для этого они могут привлекать органы местного самоуправления, занятости населения, образования и здравоохранения, общественности, реабилитационных центров и иных организаций к процессу социальной адаптации и исправлению осужденных.

Отдельным блоком закреплено проведение мероприятий, направленных непосредственно на подготовку осужденного к освобождению и последующей адаптации в обществе. Во-первых, запланированно предоставление для лиц, заканчивающих отбывание длительных сроков лишения свободы, возможности прохождения специального тренинга, включающего широкую информацию об изменениях в обществе, новых формах социальной жизни, а для некоторых категорий осужденных - предоставление возможности перевода в колонию-поселение с разрешением кратковременных выездов к месту предполагаемого жительства. Во-вторых, создание условий для подготовки освобождающихся лиц к дальнейшей постпенитенциарной адаптации через службу пробации, создание которой предусматривается Концепцией долгосрочного социально-экономического развития Российской Федерации на период до 2020 года, утвержденной распоряжением Правительства Российской Федерации от 17 ноября 2008 г. № 1662-р [23].

Таким образом, можно сделать вывод о том, что современное состояние социальной помощи и поддержки гражданам, освобождающимся из мест лишения свободы, находится в неудовлетворительном состоянии. В связи с этим существует необходимость формирования и развития позитивной информационной среды для повышения эффективности социальной адаптации лиц, освободившихся из мест лишения свободы, и для продвижения социально-значимых инициатив гражданского общества в части пенитенциарной и постпенитенциарной ресоциализации. Недостаточное взаимодействие органов государственной власти субъектов Российской Федерации, органов местного самоуправления, правоохранительных органов и институтов гражданского общества является серьезным фактором, отрицательно влияющим на эффективность мероприятий по социальной адаптации осужденных и лиц, освободившихся из мест лишения свободы.

\section{Библиография:}

1. Приказ Министерства труда и социального развития Республики Адыгея от 15.08.2013 № 174 «Об утверждении ведомственной целевой программы «Социальная реабилитация и адаптация граждан, отбывших наказание в виде лишения свободы, на 2014-2016 годы. Режим досупа: URL:http:/www.garant.ru/hotlaw/adygeia/494190/\#ixzz3h79glcOZ Постановление Кабинета Министров Республики Адыгея от 29.11.2013 № 285 «Об утверждении государственной программы Республики Адыгея «Социальная поддержка граждан» на 2014-2016 годы». Режим досyпа: URL:http:// www.mintrud-ra.org/index.php? $\mathrm{r}=11$

2. Приказ Министерства труда и социального развития Республики Алтай от 11.02.2014 № П/37 (ред. от 30.12.2014) «Об утверждении ведомственных программ» (вместе с Ведомственной целевой программой «Социальная адаптация граждан, освобожденных из мест лишения свободы, в Республике Алтай на 2016-2018 годы»). Официальный портал Республики Алтай. Режим досупа: URL: http://www.altai-republic.ru, 14.04.2014.

3. Постановление Правительства Республики Бурятия от 6.07.2012 № 411 «Об утверждении Концепции государственной политики Республики Бурятия по социальной реабилитации лиц, освободившихся из мест лишения свободы, и лиц, осужденных к наказаниям и иным мерам уголовно-правового характера без изоляции от общества». Приложение Официальный вестник к газете «Бурятия». - 2012. - № 69, - 10 июля

4. Постановление Правительства РИ от 21.08.2014 № 155 «Об утверждении государственной программы Республики Ингушетия «Социальная поддержка и содействие занятости населения» (вместе с подпрограммой 5 «Социальная реабилитация лиц, отбывших наказание в виде лишения свободы»). Ингушетия, - 2014, - № 128-131, - 28 августа.

5. Распоряжение Администрации Алтайского края от 25.04.2014 № 135-р (ред. от 18.05.2015) «Об утверждении плана комплексных мер по социальной реабилитации лиц, отбывших наказание в виде лишения свободы, в Алтайском крае на 2014-2016 годы». Сборник законодательства Алтайского края, - 2014, - № 216, -апрель, - с. 388 


\section{Право и политика $11(203) \cdot 2016$}

6. Ст. 30 Закона Забайкальского края от 03.07.2009 № 199-З3К (ред. от 08.12.2014) «О профилактике правонарушений в Забайкальском крае» (принят Законодательным Собранием Забайкальского края 24.06.2009). Забайкальский рабочий, - 2009. - № 126, - 08 июля

7. Постановление Правительства Камчатского края от 29.11.2013 № 548-П (ред. от 27.01.2015) «Об утверждении государственной программы Камчатского края «Социальная поддержка граждан в Камчатском крае на 2014 2018 годы». Официальные Ведомости, - 2013, - № 258-268, - 10 декабря

8. Закон Ставропольского края от 12.03.2015 № 19-кз «О некоторых вопросах организации и осуществления социальной адаптации лиц, освобожденных из учреждений уголовно-исполнительной системы» (принят Думой Ставропольского края 03.03.2015). Ставропольская правда, - 2015, - № 47, - 17 марта

9. П. 1. 5. 2. Постановление Правительства Белгородской обл. от 14.01.2013 № 4-пп «Об утверждении долгосрочной целевой программы «Профилактика правонарушений, борьба с преступностью, обеспечение безопасности дорожного движения в Белгородской области на 2013-2020 годы». Белгородские известия, -2013 , - № 48, - 21 марта

10. Постановление Правительства Воронежской области от 31.12.2013 № 1187 (ред. от 19.06.2015) «Об утверждении государственной программы Воронежской области «Социальная поддержка граждан». Информационная система «Портал Воронежской области в сети Интернет». Режим доступа: URL: http://www.govvrn.ru, 22.01.2014.

11. Закон Кировской области от 01.12.2011 № 98-3О «О социальной адаптации лиц, освобожденных из учреждений уголовно-исполнительной системы» (с внесением изменений Законом Кировской области от 09.12.2013 № 366-30). Законодательное собрание Кировской области (официальный сайт). Режим доступа: URL:http:// www.zsko.ru/documents/ docs/laws.php?ID=9746

12. Закон Оренбургской области от 06.11.2009 № 3186/732-IV-О3 (ред. от 28.10.2013) «Об осуществлении реабилитации и адаптации лиц, освободившихся из мест лишения свободы» (принят постановлением Законодательного Собрания Оренбургской области от 21.10.2009 № 3186). Южный Урал, - 2009. - № 171 (спецвыпуск № 77 с документами Законодательного Собрания Оренбургской области), - 21 ноября

13. Закон Омской области от 26.02.2015 № 1720-О3 «О социальной адаптации лиц, освобожденных из учреждений уголовно-исполнительной системы» (принят Постановлением ЗС Омской области от 19.02.2015 № 28). Омский вестник, -2015 , - № $8,-27$ февраля

14. Постановление правительства Самарской области от 29.11.2013 № 711 «Об утверждении государственной программы Самарской области «Обеспечение правопорядка в Самарской области на 2014-2016 годы» (в ред. Постановлений Правительства Самарской области от 20.01.2014 № 17, от 10.04.2014 № 189). Режим досупа: URL:http://docs.cntd.ru/document/ 464008538

15. Распоряжение Правительства Сахалинской области от 30.05.2012 № 381-р «Об утверждении Концепции долгосрочной целевой программы Сахалинской области «О содействии социальной реабилитации лицам, отбывшим наказание в виде лишения свободы, и развитию уголовно-исполнительной системы Сахалинской области на 2013-2016 годы». Губернские ведомости, - 2012, - № 103(4031), - 09 июня

16. Постановление правительства Сахалинской области от от 29 декабря 2012 года № 695 «Об утверждении государственной программы Сахалинской области «Обеспечение общественного порядка, противодействие преступности и незаконному обороту наркотиков в Сахалинской области на 2013-2020 годы» (с изменениями на: 31.12.2014). Губернские ведомости, - 2013, - № 14, - 26 января.

17. Указ Президента Российской Федерации от 12.05.2009 № 537 «Стратегия национальной безопасности Российской Федерации до 2020 года» (ред. от 01.07.2014). Российская газета. - 2009. - № 88. - 19 мая.

18. Распоряжение Правительства Российской Федерации от 17.11.2008 № 1662-р «Концепция долгосрочного социально-экономического развития Российской Федерации на период до 2020 года» (ред. от 08.08.2009). Собрание законодательства РФ. - 2008. - № 47. - 24 ноября.

19. Распоряжение Правительства Российской Федерации от 07.06.2006 № 839-р, Постановление Правительства Российской Федерации от 05.09.2006 № 540 «О Федеральной целевой программе «Развитие уголовно-исполнительной системы (2007-2016 годы)» (ред. от 26.12.2013). Собрание законодательства РФ. - 2006. - № 39. - 26 октября.

20. Постановление Правительства РФ от 15.04.2014 № 312 «Об утверждении государственной программы Российской Федерации «Юстиция». Собрание законодательства, - 2014. - № 18. - 05 мая.

21. Распоряжение Правительства РФ от 14.10.2010 № 1772-р (ред. от 23.09.2015) «О Концепции развития уголовноисполнительной системы Российской Федерации до 2020 года». Собрание законодательства РФ», - 2010. - № 43 - 25 октября.

22. Приложение № 4 к постановлению Правительства РФ от 15.04.2014 № 312 «Об утверждении государственной программы Российской Федерации «Юстиция» // Собрание законодательства. - 2014. - № 18. - 05 мая.

23. Распоряжение Правительства Российской Федерации от 17.11.2008 № 1662-р «Концепция долгосрочного социально-экономического развития Российской Федерации на период до 2020 года» (ред. от 08.08.2009). Собрание законодательства РФ. - 2008. - № 47. - 24 ноября

24. Кашкина Е.В., Хандогина А.В. Административный надзор за лицами, освобожденными из мест лишения свободы: проблемы правоприменительной практики // Полицейская деятельность. - 2013. - 6. - С. 375 - 379. DOI: $10.7256 / 2222-1964.2013 .6 .10133$.

25. Абатуров А.И. Становление института постпенитенциарного контроля в России $(1844-2009$ гг.) // Юридические исследования. - 2012. - 4. - С. 134 - 173. URL: http://www.e-notabene.ru/lr/article_194.html 
DOI: $10.7256 / 1811-9018.2016 .11 .17145$

При цитировании этой статьи сноска на doi обязательна

Системы стабилизации: государственный контроль

References (transliterated):

1. Kashkina E.V., Khandogina A.V. Administrativnyi nadzor za litsami, osvobozhdennymi iz mest lisheniya svobody: problemy pravoprimenitel'noi praktiki // Politseiskaya deyatel'nost'. - 2013. - 6. - C. 375 - 379. DOI: 10.7256/2222-1964.2013.6.10133.

2. Abaturov A.I. Stanovlenie instituta postpenitentsiarnogo kontrolya v Rossii (1844-2009 gg.) // Yuridicheskie issledovaniya. -2012. - 4. - C. 134 - 173. URL: http://www.e-notabene.ru/lr/article_194.html 